\title{
Health care ethics programs in U.S. Hospitals: results from a National Survey
}

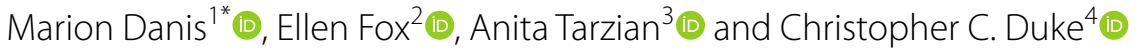

\begin{abstract}
Background: As hospitals have grown more complex, the ethical concerns they confront have grown correspondingly complicated. Many hospitals have consequently developed health care ethics programs (HCEPs) that include far more than ethics consultation services alone. Yet systematic research on these programs is lacking.

Methods: Based on a national, cross-sectional survey of a stratified sample of 600 US hospitals, we report on the prevalence, scope, activities, staffing, workload, financial compensation, and greatest challenges facing HCEPs.

Results: Among 372 hospitals whose informants responded to an online survey, 97\% of hospitals have HCEPs. Their scope includes clinical ethics functions in virtually all hospitals, but includes other functions in far fewer hospitals: ethical leadership (35.7\%), regulatory compliance (29.0\%), business ethics (26.2\%), and research ethics (12.6\%). HCEPs are responsible for providing ongoing ethics education to various target audiences including all staff (77.0\%), nurses (59.9\%), staff physicians (49.0\%), hospital leadership (44.2\%), medical residents (20.3\%) and the community/general public (18.4\%). HCEPs staff are most commonly involved in policy work through review of existing policies but are less often involved in development of new policies. HCEPs have an ethics representative in executive leadership in $80.5 \%$ of hospitals, have representation on other hospital committees in $40.7 \%$, are actively engaged in community outreach in $22.6 \%$, and lead large-scale ethics quality improvement initiatives in $17.7 \%$. In general, major teaching hospitals and urban hospitals have the most highly integrated ethics programs with the broadest scope and greatest number of activities. Larger hospitals, academically affiliated hospitals, and urban hospitals have significantly more individuals performing HCEP work and significantly more individuals receiving financial compensation specifically for that work. Overall, the most common greatest challenge facing HCEPs is resource shortages, whereas underutilization is the most common greatest challenge for hospitals with fewer than 100 beds. Respondents'strategies for managing challenges include staff training and additional funds.
\end{abstract}

Conclusions: While this study must be cautiously interpreted due to its limitations, the findings may be useful for understanding the characteristics of HCEPs in US hospitals and the factors associated with these characteristics. This information may contribute to exploring ways to strengthen HCEPs.

Keywords: Healthcare ethics, Ethics, institutional, Survey, Empirical research

*Correspondence: mdanis@nih.gov

1 Department of Bioethics, National Institutes of Health, Building 10, Rm

1C118, Bethesda, MD 20892-1156, USA

Full list of author information is available at the end of the article

\section{Background}

Hospitals are complex organizations that grapple with numerous ethical issues related to patient care, population health, professional practice, employee relations, business relations, and organizational ethics. Depending on their ownership, mission, and affiliations, some hospitals also need to be concerned with government ethics, 
public administration ethics, faith-based ethics, research ethics, and the ethics of educating trainees.

Over the past 40 years, ethics scholars, professional organizations, and oversight organizations have recognized that the breadth of ethical issues that health care organizations face are not fully encompassed by exclusive attention to the clinician-patient relationship; they have called for more attention to the range of ethical issues that are faced by health care organizations [1-4].

U.S. hospitals have tended to address this wide range of ethical issues through an expanding patchwork of committees and offices. For example, within a given hospital, clinical ethics issues are often handled by an ethics consultation service or ethics committee while business and management issues are handled by compliance officers and human resources staff and research ethics issues are handled by an institutional review board (IRB). These entities tend to operate in relative isolation from each other, instead of working together to identify and address areas of overlap and gaps [5].

Yet in more recent years, there has been a call for U.S. health care institutions to move beyond the traditional patchwork model to adopt a unified programmatic approach that integrates the various "subspecialties" of health care ethics such as clinical ethics, organizational ethics, and research ethics [6]. The American Society for Bioethics and Humanities (ASBH) has explicitly endorsed "the trend toward integrating ethics across all subspecialties in an organization" [6]. One prime example of such an integrative approach to ethics is the IntegratedEthics $^{\mathrm{TM}}$ model from the U.S. Department of Veterans Affairs National Center for Ethics in Health Care [5], which replaces the traditional, siloed, ethics committee approach with a single, overarching ethics program that coordinates and manages the organization's provision of ethics services across the full range of content domains. Other ethics models that address a wide range of ethical issues that health care organizations encounter include the Southern California region of Kaiser Permanente, whose bioethics program integrates with many programs including quality management and compliance [7], and the Catholic Health Association (CHA)/ Ascension model [8], which integrates with leadership and numerous institutional committees such as human resources (IRB), and patient relations. The cross-cutting and comprehensive nature of these programs is reflected in their mission statements. For example, the aim of the CHA/Ascension model is "to promote and support the identity and integrity of an organization and those within it; and the aim of the VA's IntegratedEthics model is "to support, maintain, and improve ethics quality in health care" at three levels. Notably, none of these integrated ethics programs focuses exclusively on clinical ethics (i.e., the identification, analysis, and resolution of values conflicts or uncertainties that arise in the provision of health care in clinical settings) $[9,10]$. Rather, they all address other ethics issues, such as those relating to resource allocation, advertising, relationships with employees, and human subjects research. Nor do these programs focus on individual decisions and actions alone; they are also concerned with the organizational systems, processes, environment, and culture [5].

Integrated ethics programs are "integrated" in three ways. First, whereas in many hospitals, ethics-related activities are carried out by various individuals and programs (such as ethics committees, leadership, and IRBs) in relative isolation from each other, integrated ethics programs have an integrative "umbrella" structure-i.e., a unified, coordinated programmatic approach. Second, whereas traditional ethics support services tend to focus on specific content areas, such as clinical ethics or research ethics, integrated ethics programs are comprehensive or at least very broad in scope, including many if not all types of ethical issues facing the organization. Third, whereas traditional ethics support services tend to focus on a narrow range of activities (e.g., ethics consultation, staff education, and policy review), integrated ethics programs employ many different strategies to accomplish their goals and integrate with other programs and individuals throughout the organization.

Despite the recent trend toward integrated programmatic approaches to ethics in health care organizations, prior empirical studies of health care ethics in U.S. hospitals have focused on a single programmatic structure, activity, or model. For example, there have been studies of clinical ethics consultation services [11-14], hospital ethics committees [15-18], clinical ethics policy [19], ethics and compliance programs [20], research ethics committees [21], and research ethics consultation [22]. But to our knowledge, no prior study has examined the full range of officially sanctioned entities within a hospital that support health care ethics-in other words, health care ethics programs (HCEPs).

To address this gap in knowledge regarding hospitalbased HCEPs in the US, we included questions regarding ethics programs in a national survey of ethics consultation in US hospitals [23]. Because ethics consultation services are often part of HCEPs, certain characteristics of ethics consultation services cannot be meaningfully studied without studying the broader ethics program. For example, budgets and staffing are often allocated to ethics programs, to cover various ethics-related activities, and not to ethics consultation services separately. While the survey was largely focused on ethics consultation, this report examines the broader context of HCEPs beyond ethics consultation. 


\section{Methods}

The broader study of which this analysis is a part [23] replicates many of the methods from a prior national study of health care ethics consultation in U.S. hospitals [11]. A full description of the methods is provided in the publication of the broader study and is accompanied by the survey instrument [23].

\section{Survey instrument}

A HCEP was defined in the survey questionnaire as follows:

\section{For this survey, health care ethics program is defined as an officially sanctioned entity within a hospital that supports health care ethics by providing ethics- related services such as ethics policy development or ethics education. Services may be performed by one or more designated individual(s), committee(s), office(s), or other organizational structure(s). A health care ethics program may or may not provide ethics consultation.}

This definition was intended to include all organized programmatic health care ethics activities regardless of how they were labeled, performed, or structured. To reinforce the idea that a HCEP is not necessarily limited to clinical ethics but can encompass a variety of other content areas, we began the survey with a question about scope that immediately followed the definition of a HCEP. Specifically, we gave a list of ethics-related functions (clinical ethics, business ethics, research ethics, regulatory compliance, ethical leadership, other) and asked respondents to select which functions their HCEP included.

Next respondents were asked a series of multiplechoice questions about the education activities, policy activities, and other activities of their HCEP. To examine their educational role, they were asked to select the target audiences to which their HCEP was responsible for providing ongoing ethics education. To examine their policy work, they were asked whether their HCEP participates in leading and/or assisting others in the development of new policies and/or the periodic review of existing policies. Regarding other activities, they asked whether their HCEP includes an ethics representative positioned at the executive leadership level in the organization, provides ethics representation to other hospital committees, leads large-scale quality improvement initiatives related to ethics, and is actively engaged in community outreach.

Respondents were also asked about their HCEP's staffing, work hours, financial compensation of staff, source of funding, and reporting relationship through numeric response, numeric range, and multiple-choice questions.
To characterize the staffing of HCEPs, respondents were asked how many individuals in total performed either paid or unpaid work for the hospital's HCEP in the last year (including ethics consultation and other ethics activities). Respondents were then asked to estimate the average number of hours per week that each of these individuals devoted to HCEP work in the last year $(<1$, $1-4,5-9,10-19,20-29,30-39$, or $\geq 40$ h/week). They were also asked how many of these individuals who worked for the HCEP received salary support (or equivalent financial compensation such as a consulting fee or a dedicated percentage of their salary) specifically for HCEP work. Respondents were then asked to estimate the total number of FTEs in salary support (or equivalent financial compensation) provided for HCEP work at their hospital. FTE was defined as follows: "FTE stands for Full-Time Equivalent. 1.0 FTE means the equivalent of one full-time salary; 0.1 FTE means the equivalent of $4 \mathrm{~h}$ per week." Respondents were asked to provide an estimate even if they did not know the exact number. To determine the source of funding, respondents were asked to indicate how this salary support (or other financial compensation) for HCEP work was funded by estimating the percentage for each of the following funding categories: hospital, multi-hospital health care system that includes the hospital, university or school, patient billing, or other.

To determine the HCEP's reporting relationship, respondents were asked which hospital administrator or senior leader had oversight responsibility for health care ethics. To clarify the meaning of oversight responsibility the following explanation was provided: "This person is not the person who leads or manages the ethics program, but rather a person at a higher leadership level in the hospital. This person would typically receive periodic reports about the ethics program and would potentially intervene if there were big problems with the program." To further characterize the program's relationship with this hospital administrator, respondents were asked to rate on a scale of 0 to 10 the administrator's level of awareness about the hospital's health care ethics activities.

Finally, to explore the challenges faced by HCEPs, respondents were asked to give detailed and specific answers to the following open-ended questions: What do you think is the \#1 greatest challenge relating to the hospital's health care ethics program right now? What do you think would help the hospital to overcome or manage that challenge? The full survey is published elsewhere [23].

Respondents in hospitals that reported not having an ethics consultation service were asked, "Is there some other individual, committee, office or other structure within your hospital that supports health care ethics by 
providing ethics-related services such as ethics policy development or ethics education?" These hospitals, which were considered to have a HCEP, were invited to take a different version of the survey that included 23 of the primary questions from the full survey ${ }^{1}$ and seven contingency questions from that survey. ${ }^{2}$

\section{Survey sample}

The survey sample was drawn from the pool of all general hospitals that participated in the 2016 American Hospital Association Annual Survey of Hospitals [24]. The random sample, stratified based on bed size category, included 600 hospitals. Survey respondents at each hospital were identified and contacted using a standardized protocol and script as described elsewhere [23].

\section{Analysis}

Data were analyzed using SAS, version 9.3. Data were weighted by bed size category to adjust for the stratified sample using the degrees-of-freedom method to make inferences about the entire population of U.S. general hospitals [25]; Descriptive statistics were used to describe survey measures. We used a series of one-way ANOVAs with contrasts and chi-squares to evaluate the associations between hospital characteristics and specific survey measures. All contrasts used the Scheffé method of adjustment for multiple comparisons [26]. We used a two-sided probability of 0.05 as the criterion for statistical significance. Results are presented as weighted percentages extrapolated from completed responses to the survey.

In addition to analyzing the survey responses, we calculated the number of content areas that were included within the scope of the hospital's HCEP (possible score range $0-5$ ), the number of educational target audiences to which the HCEP was responsible for providing ongoing ethics education (possible score range $0-7$ ), the number of types of policy work in which the HCEP participated (possible range $0-4$ ), and the number of other activities performed by the HCEP (possible range $0-4$ ). We also constructed a variable for "total workload," which was estimated from the aggregated number of person-hours per week that were devoted to (paid or unpaid) HCEP work in the last year by all of the individuals who performed work for the hospital's HCEP combined. For each of the numeric ranges specified for the average number of hours per week devoted to HCEP work by individuals, we multiplied the number of individuals whose hours per week fell in that range by the midpoint in that range, then

\footnotetext{
${ }^{1}$ Q1, Q41, Q47A-B, Q49-50, Q15, Q61-73, Q75-7.

2 Q1, Q47A, Q61, Q71, Q41, Q72.
}

summed the results across all numeric ranges. For example, if a hospital indicated that 1 person devoted between 5 and $9 \mathrm{~h}$ per week and a second person devoted $\geq 40 \mathrm{~h}$ per week, the total workload would be calculated as follows: $(1 \times 7)+(1 \times 40)=47 \mathrm{~h}$ per week.

Some responses to questions regarding average hours per week, number of individuals who received financial compensation, and FTEs did not seem plausible as explained below. For these questions, one author reviewed results to identify potentially implausible responses; these were eliminated if two other authors agreed with doing so. We report results both with and without these implausible responses.

\section{Content analysis}

Responses to open-ended questions regarding the HCEP's greatest challenge and proposed strategies to overcome this challenge were coded using content analysis as follows. Following a reading of responses, a coding scheme was developed by a research assistant. It was then reviewed and revised by one of the authors. Codes were then assigned to responses by these two individuals and reviewed by a second author. Any disagreement regarding assigned codes was reconciled by deliberation. The weighted percentage of respondents in each hospital category who provided open-ended responses matching the assigned codes was calculated. Examples of open-ended responses were selected for inclusion in this manuscript as illustrative of these codes.

\section{Results}

Study hospitals

Among the 600 sampled hospitals, one closed before data collection; 462 participated and completed all or part of the study for a response rate of $77.1 \%$. Among these participating hospitals, 438 had an ethics consultation service and were eligible for the version of the online survey designed for hospitals with ethics consultation services; 365 completed some or all of this online survey. An additional 16 of the 462 participating hospitals had a HCEP but no ethics consultation service so were eligible for the modified version of the online survey; of these 16, seven completed at least one question on that survey, but only one hospital answered any of the questions reported in this paper beyond reporting that they had a HCEP. The remaining eight of the 462 participating hospitals had no ethics consultation service and no HCEP so were not eligible for either online survey. Here we report data regarding the prevalence of HCEPS based on the 462 participating hospitals, and data about the characteristics of HCEPs based on the 372 hospitals that completed all or part of either online survey. There were no significant differences between sampled hospitals and participating 
Table 1 Prevalence and Scope of Health Care Ethics Programs (HCEPs) in US General Hospitals

\begin{tabular}{|c|c|c|c|c|c|c|}
\hline \multirow[t]{3}{*}{ Hospital category } & \multicolumn{6}{|c|}{ Population estimate (\% of hospitals) } \\
\hline & \multirow{2}{*}{$\begin{array}{l}\text { Hospital has a } \\
\operatorname{HCEP}(\mathrm{N}=462)\end{array}$} & \multicolumn{5}{|c|}{ Content areas included in the scope of HCEPs $(\mathrm{N}=291)$} \\
\hline & & Clinical ethics & Business ethics & Research ethics & $\begin{array}{l}\text { Regulatory } \\
\text { compliance }\end{array}$ & $\begin{array}{l}\text { Ethical } \\
\text { leadership }\end{array}$ \\
\hline \multicolumn{7}{|l|}{ Bed size } \\
\hline 1-99 (reference category) & 96.0 & 100 & 16.7 & 0 & 27.8 & 27.8 \\
\hline 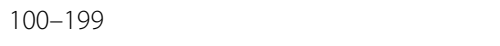 & 97.4 & 90.9 & 36.4 & 13.6 & 27.3 & 34.1 \\
\hline $200-299$ & 98.8 & 96.2 & 36.5 & 23.1 & 38.5 & 50.0 \\
\hline 300-399 & 98.5 & 100 & 31.1 & $26.7^{* *}$ & 33.3 & 46.7 \\
\hline $400-499$ & 97.7 & 97.0 & 30.3 & $36.4^{* *}$ & 18.2 & 60.6 \\
\hline $500+$ & 99.3 & 97.0 & 25.3 & $35.4^{* *}$ & 28.3 & 36.4 \\
\hline \multicolumn{7}{|l|}{ Ownership } \\
\hline Govt. (Federal) & 100.0 & 97.0 & 66.2 & 19.8 & 29.8 & 93.9 \\
\hline Govt. (non-Federal) & 98.3 & 96.6 & 37.7 & 3.9 & 16.0 & 43.4 \\
\hline Investor-owned; for-profit & 97.5 & 96.8 & 15.0 & 3.8 & 26.8 & 27.6 \\
\hline Nongovt. (not-for-profit)—church operated & 99.7 & 97.7 & 26.6 & 15.8 & 31.1 & 40.6 \\
\hline Nongovt. (not-for-profit)—other & 95.4 & 96.9 & 22.0 & 16.0 & 33.5 & 29.2 \\
\hline \multicolumn{7}{|l|}{ Academic affliation } \\
\hline Major teaching & 100.0 & 98.9 & 33.1 & $44.8^{* *}$ & 33.8 & 52.2 \\
\hline Minor teaching & 99.5 & 96.6 & 31.6 & $17.8^{* *}$ & 32.2 & 50.2 \\
\hline Non-teaching (reference category) & 95.6 & 97.1 & 21.8 & 5.2 & 26.4 & 24.2 \\
\hline \multicolumn{7}{|l|}{ Location } \\
\hline Urban & 98.8 & 96.6 & 30.5 & $27.4^{*}$ & 29.7 & 44.7 \\
\hline Rural (reference category) & 95.0 & 96.0 & 24.0 & 16.0 & 28.0 & 16.0 \\
\hline Total & 97.1 & 97.0 & 26.2 & 12.6 & 29.0 & 35.7 \\
\hline
\end{tabular}

${ }^{*} p<.01$

${ }^{* *} p<.0001$

hospitals, or between hospitals that took the online survey and all participating hospitals, for any of the hospital characteristics, as reported elsewhere [23].

\section{Prevalence of HCEPs}

Based on participants' responses, an estimated $97.1 \%$ of hospitals had a HCEP. The prevalence of HCEPs did not vary significantly by hospital bed size, ownership category, academic affiliation, or urban/rural location (see Table 1).

\section{Scope of HCEPs}

In almost all hospitals (97.0\%), the scope of the hospital's HCEP included the clinical ethics functions of the hospital. In a minority of hospitals, the HCEP scope included the hospital's ethical leadership functions (35.7\%), regulatory compliance functions (29.0\%), business ethics functions (26.2\%), and research ethics functions (12.6\%). The only significant difference across hospital categories with regard to these functions was the percentage of hospitals whose HCEPs included research ethics, as shown in Table 1.

The mean number of content areas included in the scope of hospitals' HCEPs was 2.3 (median 2, range 0 to 5). The HCEP included one content area in $43.6 \%$ of hospitals, two in $25.1 \%$, three in $18.2 \%$, four in $6.7 \%$, and all five in $5.1 \%$. The mean number of content areas varied significantly based on level of academic affiliation and hospital location (see Table 2).

\section{Activities of HCEPs}

HCEPs were responsible for providing ongoing ethics education to the following target audiences: all staff in $77.0 \%$ of hospitals, nurses in $59.9 \%$ of hospitals, staff physicians in $49.0 \%$ of hospitals, leadership/management in $44.2 \%$ of hospitals, other non-clinical staff in $40.2 \%$ of hospitals, medical residents in $20.3 \%$ of hospitals, and the community/general public in $18.4 \%$ of hospitals. These percentages did not vary significantly across hospital categories except for medical residents and staff physicians as shown in Table 3. The HCEP was responsible for one target audience in $36.8 \%$ of hospitals, two or three 
Table 2 Scope and activities of HCEPS

\begin{tabular}{|c|c|c|c|c|}
\hline \multirow[t]{2}{*}{ Hospital category } & \multirow{2}{*}{$\begin{array}{l}\text { Breadth of scope } \\
\text { Ethics content areas }\end{array}$} & \multicolumn{3}{|l|}{ Breadth of activities } \\
\hline & & $\begin{array}{l}\text { Target educational } \\
\text { audiences }\end{array}$ & Policy work & Other activities \\
\hline \multicolumn{5}{|l|}{ Bed size } \\
\hline 1-99 (reference category) & 1.7 & 2.8 & 2.3 & 1.4 \\
\hline 100-199 & 2.0 & 3.3 & 2.3 & 1.7 \\
\hline $200-299$ & $2.4^{* *}$ & 2.7 & 2.4 & 1.8 \\
\hline $300-399$ & 2.4 & 3.3 & 2.6 & 1.8 \\
\hline $400-499$ & 2.4 & 4.2 & 3.2 & 2.2 \\
\hline $500+$ & 2.2 & 3.7 & 2.8 & 1.8 \\
\hline \multicolumn{5}{|l|}{ Ownership } \\
\hline Govt. (federal) (reference category) & 3.1 & 2.0 & 2.9 & 2.0 \\
\hline Govt. (non-Federal) & 2.0 & 3.1 & 2.2 & 1.3 \\
\hline Investor-owned; for-profit & 1.7 & 2.4 & 1.7 & 1.5 \\
\hline Nongovt. (not-for-profit)—church operated & 2.1 & 3.5 & 2.6 & 1.8 \\
\hline Nongovt. (not-for-profit)—other & 2.0 & 3.1 & 2.5 & 1.7 \\
\hline \multicolumn{5}{|l|}{ Academic affiliation } \\
\hline Major teaching & $2.5^{* * * *}$ & $4.0^{*}$ & $3.1^{* * * *}$ & $2.0^{* * *}$ \\
\hline Minor teaching & $2.3^{* * * *}$ & $3.5^{*}$ & $2.8^{* * * *}$ & $1.8^{* * *}$ \\
\hline Non-teaching (reference category) & 1.7 & 2.7 & 2.1 & 1.4 \\
\hline \multicolumn{5}{|l|}{ Location } \\
\hline Urban & $1.8^{* *}$ & $2.7^{*}$ & $2.7^{* * * *}$ & $1.9^{* * * *}$ \\
\hline Rural (reference category) & 2.1 & 3.3 & 1.8 & 1.1 \\
\hline Total & 2.3 & 3.1 & 2.4 & 1.6 \\
\hline \multicolumn{5}{|l|}{${ }^{*} p<.05$} \\
\hline \multicolumn{5}{|l|}{${ }^{* *} p<.01$} \\
\hline \multicolumn{5}{|l|}{${ }^{* * *} p<.001$} \\
\hline$* * * * p<.0001$ & & & & \\
\hline
\end{tabular}

in $18.3 \%$, four or five in $29.9 \%$, and six or seven in $14.0 \%$. The mean number of target audiences was 3.1 (median 3, range $1-7)$. The number of target audiences varied significantly based on level of academic affiliation and hospital location (see Table 2).

HCEPs participated in the following types of policy work: leading the development of new policies $(52.2 \%)$, assisting others who were leading the development of new policies $(57.4 \%)$, leading periodic review of existing policies (75.5\%), and assisting others who were leading the periodic review of existing policies (55.1\%). These percentages varied based on hospitals characteristics as shown in Table 4. The mean number of types of policy work was 2.4 (median 2, range 1-4). The HCEP participated in one type of policy work in $26.2 \%$ of hospitals, two types in $35.2 \%$, three types in $10.9 \%$ and all four types in $27.7 \%$. This number of types of policy work varied significantly based on level of academic affiliation and hospital location (see Table 2).

HCEPs engaged in a variety of other activities besides education and policy work. The HCEP included an ethics representative positioned at the executive leadership level in the organization in $80.5 \%$ of hospitals, provided ethics representation to other hospital committees in $40.7 \%$ of hospitals, was actively engaged in community outreach in $22.6 \%$ of hospitals, and led large-scale quality improvement initiatives relating to ethics in $17.7 \%$ of hospitals. These activities varied based on hospital characteristics and shown in Table 4. The mean number of other activities was 1.6 (median 1 , range $1-4$ ). The HCEP performed one other activity in $61.5 \%$, two other activities in $19.7 \%$ of hospitals, three other activities in $14.7 \%$, and four other activities in $4.1 \%$. The number of other activities varied significantly based on level of academic affiliation and hospital location (See Table 2).

\section{Staffing, workload, and compensation}

The mean number of individuals who performed work (paid or unpaid) for HCEPs in the prior year was 11.0 (range $0-110$, median $=8$ ). The mean number of individuals who spent, on average, less than $1 \mathrm{~h}$ per week was 8.0 ; the number who spent $1-4 \mathrm{~h}$ per week was 
Table 3 Target audiences to which health care ethics programs have responsibility for providing ongoing ethics education ( $\mathrm{N}=278$ )

\begin{tabular}{|c|c|c|c|c|c|c|c|}
\hline \multirow[t]{2}{*}{ Hospital category } & \multicolumn{7}{|c|}{ Population estimate (\% of hospitals) } \\
\hline & All staff & $\begin{array}{l}\text { Leadership/ } \\
\text { manage-ment }\end{array}$ & Staff physicians & Medical residents & Nurses & $\begin{array}{l}\text { Non- } \\
\text { clinical } \\
\text { staff }\end{array}$ & $\begin{array}{l}\text { Community/ } \\
\text { general public }\end{array}$ \\
\hline \multicolumn{8}{|l|}{ Bed size } \\
\hline 1-99 (ref. category) & 88.2 & 47.1 & 41.2 & .00 & 58.8 & 35.3 & 11.8 \\
\hline 100-199 & 61.5 & 46.2 & 59.0 & $28.2^{* *}$ & 61.5 & 51.3 & 25.6 \\
\hline 200-299 & 74.5 & 33.3 & 39.2 & $25.5^{* *}$ & 54.9 & 29.4 & 11.8 \\
\hline 300-399 & 66.7 & 40.0 & 53.3 & $40.0^{* *}$ & 55.6 & 42.2 & 28.9 \\
\hline $400-499$ & 83.9 & 61.3 & 71.0 & $54.8^{* *}$ & 77.4 & 48.4 & 25.8 \\
\hline $500+$ & 67.4 & 35.8 & 65.3 & $62.1^{* *}$ & 64.2 & 48.4 & 31.6 \\
\hline \multicolumn{8}{|l|}{ Academic affiliation } \\
\hline Major teaching & 67.2 & 35.1 & $67.7^{* *}$ & $70.9^{* *}$ & 73.3 & 53.7 & 28.2 \\
\hline Minor teaching & 71.2 & 52.3 & $64.9^{* *}$ & $31.7^{* *}$ & 70.8 & 45.9 & 16.5 \\
\hline Non-teaching (ref. category) & 82.3 & 39.9 & 35.5 & 5.3 & 50.5 & 34.3 & 18.3 \\
\hline \multicolumn{8}{|l|}{ Location } \\
\hline Urban & 70.1 & 40.9 & $58.3^{*}$ & $45.3^{* *}$ & 62.6 & 43.7 & 24.4 \\
\hline Rural (ref. category) & 79.2 & 41.7 & 41.7 & 12.5 & 54.2 & 41.7 & 29.2 \\
\hline Total & 77.0 & 44.2 & 49.0 & 20.3 & 59.9 & 40.2 & 18.4 \\
\hline
\end{tabular}

${ }^{*} p<.01$

${ }^{* *} p<.0001$

3.0, the number who spent 5-9 $\mathrm{h}$ per week was 0.4 , the number who spent $10-19 \mathrm{~h}$ per week was 0.3 , the number who spent $20-29 \mathrm{~h}$ per week was 0.2 , the number who spent $30-39 \mathrm{~h}$ per week was 0.05 , and the number who spent 40 or more hours per week was 0.1 . Only $5.9 \%$ of hospitals had one or more individuals who worked full-time for the HCEP; $4.9 \%$ had one, $0.3 \%$ had two, $0.2 \%$ had three, $0.4 \%$ had 4 , and $0.3 \%$ had 5 . The total number of individuals who performed work for HCEPs varied based on hospital characteristics as shown in Table 5 .

The mean calculated total workload-i.e., the total number of person-hours per week devoted to paid or unpaid HCEP work in the last year by all the individuals who performed work for the HCEP combined-was 29.1 person-hours (range 0.5-1595.0, median=9). Differences across hospital categories are shown in Table 5 .

The mean number of individuals who received salary support or equivalent financial compensation such as a consulting fee or a dedicated percentage of their salary specifically for HCEP work was 1.6 (range 0-21, median $=0$ ). In $61.6 \%$ of hospitals, the respondent indicated that no individuals received financial compensation specifically for HCEP work; in $16.7 \%$ of hospitals, one individual received compensation specifically for ethics; in $6.5 \%$ of hospitals two individuals received compensation specifically for ethics; in 5.0\% of hospitals, three received compensation specifically for ethics; and in $10.2 \%$ of hospitals, four or more individuals received compensation specifically for ethics.

The mean estimate for the total number of FTEs in salary support or equivalent financial compensation provided to these individuals for HCEP work was 0.3 (range $0-15$, median $=0$ ). The estimated total FTE was 0 in $76.3 \%$ of hospitals, between 0 and 1.0 in $17.1 \%$ of hospitals, between 1.1 and 2.0 in $4.5 \%$ of hospitals, and 3 or more in $2.1 \%$ of hospitals.

In some cases, responses to the questions pertaining to these last three variables-workload, the number of individuals receiving financial compensation for HCEP work, and the total number of FTE-were deemed implausible, either because the responses were extreme outliers, or because the responses to these questions were inconsistent with each other. An example of an outlier response is one hospital where 42 individuals were reported to each spend between 20 and $29 \mathrm{~h}$ per week on HCEP work, while no individuals spent fewer than $20 \mathrm{~h}$ or more than $29 \mathrm{~h}$ per week. An example of an inconsistent response is one hospital where seven people were reported to each spend less than one hour per week on HCEP work and no one spent more than one hour per week, yet one person received salary support specifically for HCEP work and the total FTE for HCEP work was estimated to be two.

Removing such implausible responses had no effect on the results for workload. However, for both the number of individuals receiving financial compensation and 
Table 4 Policy activities and other activities of health care ethics programs

\begin{tabular}{|c|c|c|c|c|c|c|c|c|}
\hline \multirow{3}{*}{$\begin{array}{l}\text { Hospital } \\
\text { category }\end{array}$} & \multicolumn{8}{|c|}{ Population estimate (\% of hospitals) } \\
\hline & \multicolumn{4}{|c|}{ Policy activities $(\mathrm{N}=276)$} & \multicolumn{4}{|c|}{ Other activities $(\mathrm{N}=244)$} \\
\hline & $\begin{array}{l}\text { Lead policy } \\
\text { develop- } \\
\text { ment }\end{array}$ & $\begin{array}{l}\text { Assist policy } \\
\text { develop-ment }\end{array}$ & $\begin{array}{l}\text { Lead policy } \\
\text { review }\end{array}$ & $\begin{array}{l}\text { Assist } \\
\text { policy } \\
\text { review }\end{array}$ & $\begin{array}{l}\text { Represen- } \\
\text { tative in } \\
\text { executive } \\
\text { leadership }\end{array}$ & $\begin{array}{l}\text { Represen- } \\
\text { tative on other } \\
\text { committees }\end{array}$ & $\begin{array}{l}\text { Lead large- } \\
\text { scale ethics QI } \\
\text { initiatives }\end{array}$ & $\begin{array}{l}\text { Actively } \\
\text { engaged in } \\
\text { community } \\
\text { outreach }\end{array}$ \\
\hline \multicolumn{9}{|l|}{ Bed size } \\
\hline $\begin{array}{l}\text { 1-99 (ref. cat- } \\
\text { egory) }\end{array}$ & 50.0 & 43.8 & 81.3 & 50.0 & 92.9 & 21.4 & 7.1 & 14.3 \\
\hline $100-199$ & 41.0 & 66.7 & 71.8 & 51.3 & $65.7^{* * *}$ & $54.3^{* * *}$ & 22.9 & 25.7 \\
\hline $200-299$ & 56.3 & 54.2 & 68.8 & 56.3 & 88.9 & 40.0 & 26.7 & 26.7 \\
\hline $300-399$ & 64.4 & 68.9 & 71.1 & 60.0 & 63.2 & $63.2^{* * *}$ & 26.3 & 28.9 \\
\hline 400-499 & 77.4 & 87.1 & 80.6 & 71.0 & 75.0 & $75.0^{* * *}$ & 32.1 & 39.3 \\
\hline $500+$ & 59.8 & 79.4 & 68.0 & 76.3 & 63.1 & $60.7^{* * *}$ & 25.0 & 33.3 \\
\hline \multicolumn{9}{|l|}{$\begin{array}{l}\text { Academic affili- } \\
\text { ation }\end{array}$} \\
\hline Major teaching & 69.1 & $90.2^{* * *}$ & 74.3 & 71.6 & $56.7^{*}$ & $84.0^{* * *}$ & $32.4^{* * *}$ & 29.8 \\
\hline Minor teaching & 57.7 & $74.9^{* * *}$ & 79.1 & 64.9 & 79.9 & 43.0 & $28.5^{* * *}$ & 29.2 \\
\hline $\begin{array}{l}\text { Non-teachin- } \\
\text { gref. category) }\end{array}$ & 45.8 & 40.3 & 73.2 & 45.8 & 84.6 & 32.2 & 6.9 & 16.2 \\
\hline \multicolumn{9}{|l|}{ Location } \\
\hline Urban & 59.7 & $72.3^{* * *}$ & $71.9^{* * *}$ & $66.4^{* * *}$ & 70.3 & $58.6^{* *}$ & $27.0^{* * *}$ & 31.1 \\
\hline $\begin{array}{l}\text { Rural (ref. cat- } \\
\text { egory) }\end{array}$ & 47.8 & 47.8 & 65.2 & 43.5 & 81.8 & 27.3 & 4.5 & 18.2 \\
\hline Total & 52.2 & 57.4 & 75.5 & 55.1 & $80 . .5$ & 40.7 & 17.7 & 22.6 \\
\hline
\end{tabular}

for total estimated FTE, the results changed somewhat once implausible responses were removed. Specifically, for the number of individuals receiving financial compensation, for 23 of 251 respondents, responses were deemed implausible. Once these implausible responses were removed $(\mathrm{N}=228)$, the results were as follows. The mean number of individuals who received salary support or equivalent financial compensation such as a consulting fee or a dedicated percentage of their salary specifically for HCEP work was 0.6 (range $0-21$, median $=0$ ). In $71.1 \%$ of hospitals, no individuals received financial compensation specifically for HCEP work; in $16.0 \%$ of hospitals, one individual received financial compensation; in $7.2 \%$ of hospitals two received compensation; in $2.4 \%$ of hospitals, three received compensation; and in $3.3 \%$ of hospitals, four or more individuals received compensation. The number of individuals receiving financial compensation varied based on bed size, academic affiliation, and urban/rural location as shown in Table 4, which summarizes the data after implausible answers were removed.
For estimated FTEs, 17 of 204 responses were deemed implausible. Based on the plausible responses only $(\mathrm{N}=188)$, the mean estimated FTE was 0.2 (range $0-7$, median $=0$ ). Estimated FTE was 0 in $83.0 \%$ of hospitals, between 0.001 and 1.0 in $11.4 \%$ of hospitals, between 1.1 and 2.0 in $3.8 \%$ of hospitals, and 3 or more in $1.4 \%$ of hospitals. Estimated FTE varied based on bed size, academic affiliation, and location as shown in Table 5 .

When we analyze the staffing and workload of HCEPs and extrapolate from responses regarding the total number of individuals who performed paid or unpaid work for hospitals, we estimate that, in aggregate, approximately 32,000 individuals performed work for US hospital HCEPs in the year prior to the survey.

In hospitals where salary support or other financial compensation was provided for HCEP work, it was funded by the hospital in $72.9 \%$ of hospitals, by a multihospital health care system that includes the hospital in $23.3 \%$ of hospitals, by a university or school in $0.9 \%$ of hospitals, through patient billing in $0.4 \%$ of hospitals, and by some other source for $2.5 \%$ of hospitals. 
Table 5 Staffing, workload, and financial compensation for health care ethics programs (HCEPs)

\begin{tabular}{|c|c|c|c|c|}
\hline \multirow[t]{2}{*}{ Hospital category } & \multicolumn{4}{|l|}{ Mean number } \\
\hline & $\begin{array}{l}\text { Individuals who } \\
\text { performed HCEP work } \\
\text { in the last year (paid and } \\
\text { unpaid) } N=269\end{array}$ & $\begin{array}{l}\text { Workload (Person-hours/ } \\
\text { week) of individuals who } \\
\text { performed HCEP work } \\
N=251\end{array}$ & $\begin{array}{l}\text { Individuals who received } \\
\text { financial compensation } \\
\text { specifically for HCEP work } \\
\mathrm{N}=228 \S\end{array}$ & $\begin{array}{l}\text { Estimated FTEs (full-time } \\
\text { equivalents) provided for } \\
\text { HCEP work } N=188 \S\end{array}$ \\
\hline \multicolumn{5}{|l|}{ Bed size } \\
\hline 1-99 (ref. category) & 6.6 & 5.6 & 0.1 & 0 \\
\hline 100-199 & 10.0 & 19.8 & 0.7 & 0.1 \\
\hline 200-299 & $15.2^{* * * *}$ & 50.8 & 1.1 & 0.1 \\
\hline $300-399$ & $18.9^{* * * *}$ & 39.2 & 0.7 & 0.1 \\
\hline $400-499$ & 15.5 & 76.3 & 1.3 & 0.7 \\
\hline $500+$ & $20.8^{* * * *}$ & $104.0^{* * * *}$ & $2.1^{* * *}$ & $1.0^{* * * *}$ \\
\hline \multicolumn{5}{|l|}{ Academic affiliation } \\
\hline Major teaching & $19.3^{* * * *}$ & $109.6^{* * * *}$ & $2.1^{* *}$ & $1.0^{* * * *}$ \\
\hline Minor teaching & $13.9^{* * * *}$ & 29.6 & 0.6 & 0.2 \\
\hline Non-teaching (ref. category) & 7.9 & 17.3 & 0.5 & 0 \\
\hline \multicolumn{5}{|l|}{ Location } \\
\hline Urban & $17.1^{* * * *}$ & $41.8^{* *}$ & $0.9^{* *}$ & $0.2^{*}$ \\
\hline Rural (ref. category) & 9.4 & 6.6 & 0.1 & 0 \\
\hline Total & 11.0 & 29.1 & 0.6 & 0.2 \\
\hline \multicolumn{5}{|l|}{${ }^{*} p<.05$} \\
\hline \multicolumn{5}{|l|}{${ }^{* *} p<.01$} \\
\hline \multicolumn{5}{|l|}{$* * * p<.001$} \\
\hline${ }^{* * * *} p<.0001$ & & & & \\
\hline
\end{tabular}

\section{Reporting relationship}

The hospital administrator or senior leader who had oversight responsibility for health care ethics was the Chief Executive Office in $28.4 \%$ of hospitals, the Chief Medical Officer in $23.8 \%$ of hospitals, the Chief Nursing Officer in $18.7 \%$ of hospitals, the Chief Operating Officer in $4.7 \%$ of hospitals, and some other individual in $24.4 \%$ of hospitals. The mean rating for the hospital administrator's level of awareness about the hospital's health care ethics activities was 8.1 on a scale from 0 to 10 (where $0=$ not at all aware and $10=$ extremely aware).

\section{Greatest challenges facing ethics programs}

Of the 372 respondents who completed some part of the online survey, 232 wrote in responses describing their HCEP's \#1 greatest challenge. The greatest challenges fell into 5 categories: resource shortages (including time, money, staff, recruitment, and training); underutilization of the ethics support services (i.e., staff were unaware of the service, did not understand the role of the service, did not appreciate its possible benefits, or did not identify a need for the service); lack of clarity about the ethics program's scope, goals or purpose; lack of support from organizational leaders; and other challenges. See Table 6 for a summary of the percentages of hospitals reporting these challenges and sample quotes for each category. Hospitals with 1-99 beds were much more likely to report underutilization (50\%) as their greatest challenge than hospitals with $500+$ beds $(16.5 \%)(p<0.01)$. Similarly, non-teaching hospitals $(44.3 \%)$ and rural hospitals (38.9\%) were much more likely to report underutilization as their greatest challenge than major teaching hospitals $(9.0 \%)$, and urban hospitals $(19.6 \%)(p<0.0001)$. Meanwhile, large hospitals, major teaching hospitals, and urban hospitals were more likely to list resource shortages as their greatest challenge $(63.3 \%$ of hospitals with $500+$ beds vs. $42.9 \%$ of hospitals with $1-99$ beds; $69.5 \%$ of major teaching vs. $47.9 \%$ of non-teaching hospitals; $55.6 \%$ urban vs. $44.4 \%$ rural hospitals), although the differences for resource shortages were not statistically significant. While resource shortages was the most commonly reported greatest challenge overall, underutilization was the most commonly reported greatest challenge in hospitals with fewer than 100 beds.

\section{Strategies for overcoming challenges}

Responses regarding what the respondent thought would help their hospital overcome or manage their greatest challenge fell into 8 categories: additional resources (for more time, staff, or other needs); training for staff; 
Table 6 The \#1 greatest challenges faced by health care ethics programs (HCEPs) $(\mathrm{N}=232)$

\begin{tabular}{|c|c|c|}
\hline Type of challenge & $\%$ of hospitals ${ }^{a}$ & Illustrative quotes \\
\hline $\begin{array}{l}\text { Resource shortages (time, money, staff, recruitment, and train- } \\
\text { ing) }\end{array}$ & 48.5 & $\begin{array}{l}\text { Lack of time and training of some committee members, especially } \\
\text { the physician members } \\
\text { As awareness about our services grows the demand grows too, } \\
\text { but without additional financial support we are unable to meet } \\
\text { the demand. Additionally, while we have targeted known high- } \\
\text { need areas, without further financial support we are unable } \\
\text { to educate the institution more broadly or assess needs and } \\
\text { develop initiatives to target other areas } \\
\text { Not enough hours in the day/personnel to be present across the } \\
\text { house }\end{array}$ \\
\hline Underutilization of HCEP services & 34.0 & $\begin{array}{l}\text { Lack of interest in ethics unless it is to back up a doctor who is } \\
\text { making a difficult decision. There is a sense that attendings don't } \\
\text { know why an ethics consultant would ever question an attend- } \\
\text { ing's decision, even though attendings don't always see how } \\
\text { ethically complicated a decision might be }\end{array}$ \\
\hline Other & 22.1 & $\begin{array}{l}\text { Relationship building } \\
\text { Making ethics a priority alongside issues of improving quality } \\
\text { metrics }\end{array}$ \\
\hline Lack of clarity about the HCEP's goals or purpose & 4.6 & $\begin{array}{l}\text { Defining/delineating scope with overlapping services (e.g., social } \\
\text { work, palliative care) } \\
\text { Clarification between clinical bioethics and "ethics and compli- } \\
\text { ance (ECO)" related issues }\end{array}$ \\
\hline Lack of support for the HCEP from organizational leadership & 3.8 & $\begin{array}{l}\text { For me, it is the notion of buy in, whether financially, personnel } \\
\text { resourcing, commitment from Senior Leadership. Currently, } \\
\text { Healthcare Ethics at our Institution seems to be viewed as "oh } \\
\text { it's nice to have, but we're not going to commit the resources to } \\
\text { really developing and strengthening it." }\end{array}$ \\
\hline
\end{tabular}

a Percentages are population estimates determined by weighting the sampling adjustments. Because responses were given multiple codes when they illustrated more than one type of challenge, percentages exceed $100 \%$

increased leadership buy-in; publicity or marketing; quality improvement efforts; data to demonstrate the value of the program; regional or national support or mandate; or some other solution that fell outside of these categories. See Table 7 for percentages of hospitals reporting each of these categories and sample quotes. Government hospitals were more likely to mention training as a solution than were for-profit hospital (Federal government (0.45), non-federal government (0.62), for-profit $(0.18), p<0.01)$.

\section{Discussion}

This nationwide survey of a random sample of US hospitals serves to describe the characteristics of HCEPs in US hospitals beyond ethics consultation. The characteristics we studied were: prevalence, scope, activities (education, policy, other activities), staffing, workload, financial compensation for program staff, reporting relationship, the \#1 greatest challenge, and potential solutions.

\section{Limitations}

We wish to note several limitations before putting the study in context and considering its implications. We should acknowledge that we may have overestimated the percentage of hospitals that have HCEPs since hospitals without such a program may have been less likely to have a "best informant" and therefore less likely to have participated in the study. However, there were no significant differences between participating hospitals and non-participating hospitals for any of the demographic variables examined in this study [23]. Another limitation is that among hospitals that said they had a HCEP, only one hospital without an ethics consultation service responded to the questions reported in this study. Thus while this study was designed to provide information on HCEPS in hospitals that provide ethics consultation as well as those that do not provide ethics consultation, the results provide almost no information about hospitals in the latter category. A further limitation relates to the completion of the survey by a single respondent or "best informant" at each hospital. Since in many hospitals, various ethics-related activities are carried out in silos in relative isolation from each other [5], the survey respondent may not have been aware of the full range of activities of their HCEP, especially if the program was not well integrated. An added challenge is that unlike EC, which has widely accepted definitions and standards, there are no widely accepted definition or standards for HCEPs. While we stipulated a definition for "health care ethics program" in the survey, the term has only recently been gaining in usage and acceptance with the trend towards adopting integrated 
Table 7 Proposed strategies for overcoming challenges of health care ethics programs (HCEPs) (N=232)

\begin{tabular}{|c|c|c|}
\hline Type of Strategy & $\%$ of hospitals ${ }^{a}$ & Illustrative quotes \\
\hline Training for existing staff & 37.2 & $\begin{array}{l}\text { Webinars on types of ethical issues in rural facilities } \\
\text { Online training } \\
\text { Internal training or hire a lead clinical ethicist } \\
\text { Perhaps education of medical staff on the real components of an ethics consult } \\
\text { and the procedures in place that govern our work }\end{array}$ \\
\hline Funds for additional time, staff, or other needs & 30.3 & $\begin{array}{l}\text { More budgetary support for clinical ethics } \\
\text { Our efforts to make a case for increased funding include ... ongoing conversations } \\
\text { with administration; most recently exploring philanthropic means of funding. It } \\
\text { really comes down to funding }\end{array}$ \\
\hline Other & 29.5 & $\begin{array}{l}\text { Stabilizing a team will require leadership that is willing to make changes that unify } \\
\text { the group to a shared sense of purpose } \\
\text { Set up triggers for ethics consults } \\
\text { It would help if physicians involved in ethics cases took ethics committee recom- } \\
\text { mendations seriously, when the recommendations conflicted with their own } \\
\text { inclinations }\end{array}$ \\
\hline Increased leadership buy-in & 9.4 & $\begin{array}{l}\text { A strategic plan for Bioethics at (Hospital) presented to the Hospital Board. We } \\
\text { should be responsible for an annual report to the board as well }\end{array}$ \\
\hline Data demonstrating value of HCEPs & 8.0 & $\begin{array}{l}\text { Refrain from evaluating the quality of ethics services according to patient satisfac- } \\
\text { tion, length of stay, or other 'traditional' quality metrics } \\
\text { The ability to make a sound business case to get the ethicist position approved }\end{array}$ \\
\hline Publicity/marketing & 6.0 & $\begin{array}{l}\text { Having or developing a Marketing tool } \\
\text { promotion of awareness of the ethics committee functions }\end{array}$ \\
\hline Regional/national support or mandate for HCEPs & 5.5 & $\begin{array}{l}\text { There is a (state) network that we are aware of and somewhat connected to, but } \\
\text { we are not "members" of per se } \\
\text { Mandates by regulatory and accreditation agencies } \\
\text { National norms for adequate support }\end{array}$ \\
\hline Quality assurance/quality improvement & 5.2 & $\begin{array}{l}\text { development of quality measures to assess the benefit of clinical ethics consulta- } \\
\text { tion } \\
\text { quality review of current consult and a formalized process for curbside consults } \\
\text { Making demonstration of ethics knowledge a performance standard }\end{array}$ \\
\hline
\end{tabular}

a Percentages are population estimates determined by weighting the sampling adjustments. Because responses were given multiple codes when they illustrated more than one type of challenge, percentages exceed $100 \%$

ethics programs. In this survey, because we wanted to capture the full range of organized entities that support health care ethics, we deliberately defined HCEPs in a broad and general way. As such, the term was almost certainly interpreted differently by various respondents. Lastly, a limitation of the paper relates to the questions on salary support/compensation and our concerns about the validity of these results, because of both the number of non-respondents and the number of implausible responses observed for these questions.

\section{Prevalence, scope, and activities of HCEPs}

Having acknowledged these limitations, we believe these data serve as the first systematically conducted survey of the state of HCEPs in US hospitals. It represents a starting point for further research and may serve to set a bar for future work. As such, we reflect on the study findings and their implications. The $97 \%$ prevalence of HCEPs in US hospitals is not surprising, considering that by 1999 , 93\% of hospitals had institutional ethics committees. We expected the prevalence of HCEPs to be quite high since HCEPs were defined to encompass all organized health care ethics activities including but not limited to ethics committees.

With regard to scope of HCEPs, our findings show that in almost all hospitals, HCEPs include the hospital's clinical ethics functions, while other functions such as ethical leadership, research ethics, regulatory compliance, and business ethics were included in the scope of the HCEP in only a minority of hospitals. We should note that there are two possibilities for why hospitals do not report that the scope of their HCEP includes a particular function or content area: either that function is not carried out under the umbrella of the HCEP, or that function is not carried out at the hospital at all-at least not in an organized way. For example, a hospital might have an internal or external IRB that addresses aspects of research ethics but is separate from the hospital's HCEP, or alternatively, the hospital might have no organized mechanism for addressing research ethics at all, which would likely be the case if they did not conduct research. While historically, most clinical research was conducted in academic medical centers, which comprise approximately $5 \%$ of hospitals in the U.S. [27], there has been a trend in favor 
of community hospitals conducting research [28], and now most health care facilities have at least one IRB [29]. In this study $12.6 \%$ of hospitals indicated that research ethics functions were within the scope of their HCEPs, but there may have been other hospitals that addressed research ethics separately from their HCEP.

With regard to the other content areas (ethical leadership, business ethics, regulatory compliance), only a minority of hospitals report that they are included in their HCEPs. While there is little doubt that all hospitals encounter ethical issues relating to all three of these content areas, it is unclear whether hospitals formally address ethics in these areas through programs or structures separate from their HCEPs, or not at all. As an example, all hospitals must meet regulatory compliance requirements [28]. Guidance from the U.S. Department of Health and Human Services Office of the Inspector General states that "it is imperative for hospitals to establish and maintain effective compliance programs" [30]. So, while only $29 \%$ of respondents reported that this activity resided with their HCEP, compliance activities are highly likely to be going on elsewhere in the hospital. Compliance programs are often called "Compliance and Ethics" programs, mirroring U.S. Sentencing Commission Guidelines for Organizations [31]. But it is unclear the extent to which compliance programs integrate both compliance-based and values- or integrity-based approaches to ethics [32].

HCEPs were much more likely to engage in certain activities compared to others. Most hospitals' HCEPs were responsible for providing ongoing ethics education to all staff and to nurses, while a minority of hospitals were responsible for educating other target audiences. In terms of policy work, HCEPs most commonly reviewed existing policies and less often participated in developing new policies or assisting others in policy review. Most HCEPs had a representative in executive leadership, but less than half had representatives on other committees, led large-scale quality improvement initiatives relating to ethics, and engaged in community outreach.

\section{Extent of integration of HCEPs}

Our findings pertaining to the scope and activities of HCEPs provide some preliminary insights into the degree to which HCEPs are integrated. Integrated ethics programs, by their nature, have a unified, coordinated structure; are comprehensive or at least very broad in scope, and utilize a variety of different strategies to integrate with other programs and individuals throughout the organization. In this survey we did not examine the extent to which HCEPs are unified or coordinated structurally, but we did ask questions about the breadth of HCEPs scope and activities. With respect to scope, we note that while in most hospitals the HCEP's scope was rather narrow, in that it included only one or two of the listed content areas, in $11.8 \%$ of hospitals, the scope was broad, in that they included four or five of these areas. We also note that the mean number of content areas varied based on level of academic affiliation, suggesting that HCEPs in academic medical centers tend to be broader in scope.

We observed a similar pattern for HCEPs' breadth of activities. In most hospitals the HCEP was responsible for educating only a few of the listed target audiences, but in $14.0 \%$ of hospitals the HCEP educated six or seven. In most hospitals the HCEP participated in only one or two of the listed types of policy work, but in $27.7 \%$ the HCEP participated in all four. And in most hospitals the HCEP performed only one of the other activities listed, but in $4.1 \%$ of hospitals, the HCEP participated in all four. For all of these variables-content areas, target audiences, types of policy work, and other activities, the mean number varied based on level of academic affiliation and location, suggesting that HCEPs in urban academic medical centers tend to be more integrated.

\section{Staffing, workload, and compensation for HCEP work}

In reflecting on the study results regarding compensation for HCEP work, we must take into account that, with respect to both the number of individuals who received financial compensation and the estimated number of FTEs, there were a number of non-respondents to these questions and a number of participants gave responses that were considered implausible. This suggests that respondents may not have been sure about how to answer these questions and/or may have misinterpreted their intent. Hence any interpretation must be cautious. Nonetheless, a few observations deserve mention.

First, we observe that the estimated number of individuals who performed work for HCEPs in US hospitals in the year prior to the survey was 32,000, compared with 27,000 who performed ethics consultation [23]. This would suggest that $84 \%$ of individuals who work for HCEPs perform ethics consultation.

Second, it appears that large hospitals, major teaching hospitals, and urban hospitals devoted significantly more resources to HCEPs than other hospitals, in term of individuals working for the HCEP, the number of person hours spent on HCEP work, the number of individuals receiving financial compensation specifically for HCEP work, and the total number of FTEs. With respect to financial compensation, the differences were particularly striking: for example, the mean number of FTEs for hospitals with 500 or more beds and for major teaching hospitals was 1.0, compared with 0 for hospitals with fewer than 100 beds and for non-teaching hospitals. 
In interpreting these results, it is important to note that the survey asked only about individuals who received financial compensation specifically for HCEP work in the form of, for example, a consulting fee or a dedicated percentage of their salary. Employees who performed work for the HCEP as a volunteer service activity, as a "collateral duty," or as part of their administrative or protected time may have been $100 \%$ compensated for their HCEP work in the sense that they performed it while "on the clock," even though they did not receive any compensation specifically for their HCEP work. In addition, while percent effort distribution (in which professionals have portions of their time allocated to specific activities) is a common practice in academic medical centers, this may be an unfamiliar concept in non-academic settings. As a result, this study may have underestimated financial compensation in these hospitals.

\section{Challenges and solutions}

As we noted, while overall, a shortage of resources was the most commonly reported greatest challenge, in hospitals with fewer than 100 beds, the most commonly reported greatest challenge was underutilization. Responses categorized as underutilization included lack of staff awareness, understanding, or appreciation of the services offered by the HCEP, or lack of perceived need for the service. This finding of underutilization is consistent with the findings of a national survey of critical access hospitals conducted in 2007 [33]. In that survey, which included 381 hospital administrators, only $60 \%$ of these hospital administrators reported having an ethics committee or ethics consultation service and $28 \%$ did not see the need for such ethics support services despite their absence [33]. Is the challenge of underutilization at small hospitals concerning? It would seem to depend on whether health care professionals do in fact have the competence to address ethical concerns without collaborating with health care ethicists, and are doing so in a way that adequately and justly meets the needs of stakeholders at their hospitals. Our study cannot adequately determine whether that is the case, but it is an important issue to explore.

\section{Conclusion}

Given the complicated mission and organizational structure of hospitals, and the many stakeholders involved, hospital leaders have a daunting task in meeting their mission in an ethically sound manner. Our study shows that nearly all US hospitals have some sort of HCEP, but these programs vary widely in terms of scope, activities, staffing, workload, and compensation of staff. Only a minority of HCEPs are integrated ethics programs in that they apply a unified, coordinated programmatic approach to managing ethics that address a broad range of ethics content areas and employ a wide range of strategies to integrate with other parts of the organization. The greatest challenge facing HCEPs is lack of resources, except in small hospitals where the greatest challenge is underutilization. We hope that our results will inform further discussion about the appropriate role of HCEPs and the resources they require in facilitating the delivery of ethically sound patient care in hospitals.

\section{Abbreviations \\ ASBH: American Society for Bioethics and Humanities; CHA: Catholic Health Association; FTE: Full time equivalent; HCEP: Health care ethics program; IRB: Institutional Review Board.}

\section{Acknowledgements}

The authors would like to thank the following Altarum employees for their help on this work: Gillian Beach, Gregory Becker, Cydny Black, Elizabeth Blair, Erin Butto, Danisha Herrod, Jim Lee, Christine Stanik. We would also like to thank Paula Goodman-Crews and Alexander Kon for their valuable contributions to the expert panel, and Lisa Lehmann for her early involvement in the project. Finally, we would like to thank the hundreds of individuals and hospitals that participated in cognitive interviewing, pilot testing, or the survey study.

\section{Authors' contributions}

$\mathrm{EF}, \mathrm{MD}, \mathrm{AT}$, and CD made substantial contributions to the conception and design of the survey, interpretation of the data and preparation of the manuscript; EF and CD made substantial contribution to acquisition of the data. EF, CD and MD contributed to the analysis, of the data. All authors have approved the submitted version of the study. All authors have agreed both to be personally accountable for their own contributions and to ensure that questions related to the accuracy or integrity of any part of the work, were appropriately investigated, resolved, and the resolution documented in the literature. All authors read and approved the final manuscript.

\section{Funding}

Open Access funding provided by the National Institutes of Health $(\mathrm{NIH})$. This work was supported by the Greenwall Foundation under a 2015 Making a Difference Grant and a 2018 President's Award. Marion Danis's salary was supported by the Department of Bioethics, a part of the intramural program at the National Institutes of Health. The funders had no role in data collection, analysis or reporting.

\section{Availability of data and materials}

The datasets generated and analyzed during this study may be requested from the authors. Because some survey data may reveal identifying information regarding participating hospitals, access to some data may be restricted.

\section{Declarations}

\section{Ethics approval and consent to participate}

This study was performed in accordance with relevant guidelines and regulations. The survey was reviewed and determined to be exempt from IRB review by the Chesapeake (now Advarra) IRB and the Office of Human Subjects Research Protection (OHSRP) at the National Institutes of Health. The OHSRP determination specified that Federal regulations for the protection of human subjects do not apply to this study. The OHSRP determination of Not Human Subjects Research is based on the interpretation of 45 CFR 46 under "Research Involving Coded Private Information or Biological Specimens" [34] and Guidance on Engagement of Institutions in Human Subjects Research [35]. The activity was designated EXEMPT, and was entered in the OHSRP database (Exempt \#13456).

Consent for publication

No personally identifying information was included in this research. 


\section{Competing interests}

The authors declare that they have no conflict of interest related to this work.

\section{Disclaimer}

The views expressed here are those of the authors and are not necessarily a reflection of the policies of their employers.

\section{Author details}

${ }^{1}$ Department of Bioethics, National Institutes of Health, Building 10, Rm 1C118, Bethesda, MD 20892-1156, USA. ${ }^{2}$ Fox Ethics Consulting, Arlington, VA 22213, USA. ${ }^{3}$ National Center for Ethics in Health Care, Veterans Health Administration, 811 Vermont St. NW., Washington, DC 20571, USA. ${ }^{4}$ Altarum Institute, 3520 Green Ct., Suite 300, Ann Arbor, MI 48105, USA.

Received: 21 April 2021 Accepted: 14 July 2021

Published online: 29 July 2021

\section{References}

1. Potter RL. From clinical ethics to organizational ethics: the second stage of the evolution of bioethics. Bioethics Forum. 1996;12(2):3-12.

2. JCAHO Standard RI. 1.1.6.1. 1992. In: comprehensive accreditation manual for hospitals. Joint Commission on the Accreditation of Healthcare Organizations. Oakbrook Terrace (IL); 1992.

3. Woodstock Theological Center. Ethical considerations in the business aspects of health care. Georgetown University Press; 1995.

4. American College of Healthcare Executives. Code of ethics: As amended by the Council of Regents at its annual meeting on March 25, 2000. http://www.ache.org/abt_ache/code.cfm (2021). Accessed 16 June 2021.

5. Fox E, Bottrell MM, Berkowitz KA, Chanko BL, Foglia MB, Pearlman RA. IntegratedEthics: an innovative program to improve ethics quality in health care. Innov J. 2010;15(2):1-36.

6. ASBH American Society for Bioethics \& Humanities' Core Competencies Update Task Force. Core competencies for health care ethics consultation: Report of the American Society for Bioethics and Humanities. 2nd ed. Glenview (IL): American Society for Bioethics and Humanities; 2011.

7. Kusterbeck S. Kaiser Permanente changes landscape for hospital ethics. 2011. https://www.reliasmedia.com/articles/131627-kaiser-permanentechanges-landscape-for-hospital-ethics. Accessed 16 June 2021.

8. Catholic Health Association (CHA) of the United States, Ascension Health. Striving for excellence in ethics: A resource for the Catholic health ministry. St. Louis (MO): Catholic Health Association of the United States; 2011.

9. Fletcher JC, Boyle R, editors. Introduction to clinical ethics. 2nd ed. Frederick (MD): University Publishing Group; 1997.

10. Jonsen AR, Siegler M, Winslade WJ. Clinical ethics: a practical approach to ethical decisions in clinical medicine. 5th ed. New York: McGraw-Hill; 2002.

11. Fox E, Meyers S, Pearlman RA. Ethics consultation in United States hospitals: a national survey. Am J Bioeth. 2007;7(2):13-25.

12. Godkin D, Faith KE, Upshur R, Macrae K, Tracy CS. Project Examining Effectiveness in Clinical Ethics (PEECE): phase 1-descriptive analysis of nine clinical ethics services. J Med Ethics. 2005;31(9):505-12.

13. Kesselheim JC, Johnson J, Joffe S. Ethics consultation in children's hospitals: results from a survey of pediatric clinical ethicists. Pediatrics. 2010;125(4):742-6.

14. McClung JA, Kamer RS, DeLuca M, Barber HJ. Evaluation of a medical ethics consultation service: opinions of patients and health care providers. Am J Med. 1996;100:456-60

15. McGee G, Caplan AL, Spanogle JP, Asch DA. A national study of ethics committees. Am J Bioeth. 2001;1(4):60-4.

16. McGee GE, Spanogle JP, Caplan AL, Penny D, Asch DA. Successes and failures of hospital ethics committees: a national survey of ethics committee chairs. Camb Q Healthc Ethics. 2002;11(1):87-93.
17. Moon M. Committee on bioethics. Institutional Ethics Committees. Pediatrics. 2019;143(5):e20190659. https://doi.org/10.1542/peds.2019-0659.

18. Youngner SJ, Jackson DL, Coulton C, Juknialis BW, Smith EM. A national survey of hospital ethics committees. Crit Care Med. 1983;11(11):902-5.

19. Frolic AK, Drolet K, Bryanton K, Caron C, Cupido C, Flaherty B, Fung S, McCall L. Opening the black box of ethics policy work: evaluating a covert practice. Am J Bioeth. 2012;12(11):3-15.

20. Beckers Hospital Review. 10 statistics on healthcare compliance and ethics programs. 2020. https://www.beckershospitalreview.com/legal-regul atory-issues/10-statistics-on-healthcare-and-ethics-programs. Accessed 16 June 2021.

21. Catania JA, Lo B, Wolf LE, Dolcini MM, Pollack LM, Barker JC, Wertlieb S, Henne J. Survey of US human research protection organizations: workload and membership. J Empir Res Hum Res Ethics. 2008;3(4):57-69.

22. Porter K, Danis M, Taylor H, Cho M, Wilfond B. The emergence of clinical research ethics consultation: insights from a national collaborative. Am J Bioeth. 2017;18(1):39-45.

23. Fox E, Danis M, Tarzian A, Duke CD. Ethics consultation in U.S. hospitals: a national follow-up study. Am J Bioeth. 2021;5:4. https://doi.org/10.1080/ 15265161.2021.1893547.

24. AHA Annual Survey Database. American Hospital Association, Washington. 2016. https://www.ahadata.com/aha-annual-survey-database\#.

25. Maletta H. Weighting. 2007. https://www.spsstools.net/static/resources/ WEIGHTING.pdf. Accessed 16 June 2021.

26. Scheffé H. The analysis of variance. 1999. New York: Wiley; 1959.

27. Advisory Board. Why some universities are bidding adieu to academic medical centers. 2015. https://www.advisory.com/daily-briefing/2015/04/ 24/universities-dropping-amcs. Accessed 16 June 2021.

28. Glabman M. Community hospitals branch out to clinical research. 2008 https://acphospitalist.org/archives/2008/12/research.htm. Accessed 16 June 2021.

29. Grady C. Institutional review boards: purpose and challenges. Chest. 2015;148(5):1148-55.

30. Department of Health and Human Services Office of Inspector General. OIG Supplemental Compliance Program Guidance for Hospitals. In: Federal Register. 2005;70(19):4858. https://oig.hhs.gov/fraud/docs/compl ianceguidance/012705HospSupplementalGuidance.pdf. Accessed 16 June 2021.

31. United States Sentencing Commission. Federal Sentencing Guidelines. Chapter. Chapter 8 - Sentencing of Organizations. 2018. https://www. ussc.gov/guidelines/2018-guidelines-manual/annotated-2018-chapt er-8\#NaN. Accessed 16 June 2021.

32. Geddes $\mathrm{BH}$. Integrity of compliance based ethics: which is better for today's business? Open J Bus Manag. 2017. https://doi.org/10.4236/ojbm. 2017.53036.

33. Nelson WA, Rosenberg MC, Mackenzie T, Weeks WB. The presence of ethics programs in critical access hospitals. HEC Forum. 2010;22:267-74.

34. Office of Human Research Protection. Coded Private Information or Specimens Use in Research, Guidance. 2008. https://www.hhs.gov/ohrp/ regulations-and-policy/guidance/research-involving-coded-private-infor mation/index.html. Accessed 7 July 2021.

35. Office of Human Research Protection. Engagement of Institutions in Human Subjects Research. 2008. https://www.hhs.gov/ohrp/regulationsand-policy/guidance/guidance-on-engagement-of-institutions/index. html. Accessed 7 July 2021

\section{Publisher's Note}

Springer Nature remains neutral with regard to jurisdictional claims in published maps and institutional affiliations. 